\title{
Perspectivas y problemáticas sobre el Mundial Argentina 78. Infraestructuras, gubernamentalidades y festejos populares
}

Roldán, Diego

Universidad Nacional de Rosario - CONICET, Argentina

diegrol@ hotmail.com

Cita sugerida: Roldán, D. (2018). Perspectivas y problemáticas sobre el Mundial Argentina 78. Infraestructuras, gubernamentalidades y festejos populares. Cuestiones de Sociología, 18 e056. https://doi.org/10.24215/23468904e056 


\title{
Perspectivas y problemáticas sobre el Mundial Argentina 78. Infraestructuras, gubernamentalidades y festejos populares
}

\author{
Perspectives and problems about the Argentina World Cup 78. Infrastructures, governmentalities and popular \\ celebrations \\ Diego Roldán \\ Universidad Nacional de Rosario - CONICET, Argentina \\ diegrol@hotmail.com
}

\section{Resumen:}

Este trabajo presenta tres problemas que produjeron la gubernamentalidad del XI mundial de fútbol. Primero, la generación de condiciones de posibilidad: la construcción de infraestructuras urbanas y comunicacionales para el evento. Segundo, las convergencias de las tecnologías de gobierno militar y de gobierno deportivo. Tercero, el desarrollo paradójico de movimientos y corporalidades contenidas y reguladas en la ceremonia inaugural y unos cuerpos-performances carnavalescos en los festejos callejeros luego de la final. Palabras clave Modernización - Gubernamentalidad-- Disciplinamiento - Dictadura - Deporte

Palabras Clave: Modernización, Gubernamentalidad-, Disciplinamiento, Dictadura, Deporte.

\section{ABSTRACT:}

The article presents three problems that produced the governmentality of the XI World Cup. First, the generation of conditions of possibility: the construction of urban and communication infrastructures for the event. Second, the convergences of military government and sports governance technologies. Third, the paradoxical development of movements and corporalities contained and regulated in the inaugural ceremony and carnival bodies-performances in the street celebrations after the final.

KEYWORDS: Modernization, Governmentality, Discipline, Dictatorship, Sport.

\section{INTRODUCCIÓN}

El pasado realmente no existe como tal. No hay una experiencia intacta, pura, original que uno pueda decir: eso es el pasado. Esa experiencia que uno llama el pasado está todo el tiempo siendo reescrita, reelaborada, repensada. Alan Pauls

Alrededor del Mundial78 se tejieron distintas interpretaciones. Una se fundó en el ejercicio del periodismo y arrojó resultados desparejos. Dos ejemplos de esa disparidad son los libros de Gilbert y Vitagliano (1998) y Llonto (2005). También la literatura compuso obras en las que esta temática apareció como marco de la acción. En este ámbito, cabe destacar la novela sobre la vigilancia de la vida cotidiana de Antonio DalMasetto (1998) y la notable yuxtaposición del Mundial 78 con la Guerra de Malvinas que propone Martín Kohan (2002). Finalmente,una serie de piezas breves de las ciencias sociales abordaron al mundial. Solo mencionaré algunos aportes en la sociología de la cultura y el deporte (Alabarces, 2004 y 2014), la antropología del deporte (Archetti, 2004) y la historiografía del fútbol (Ferrero y Sazbón, 2007). Se trata de estudios concentrados en la organización del campeonato, la propaganda, las relaciones entre fútbol y nación y la apropiación del régimen dictatorial de la euforia popular. En este campo hermenéutico, es llamativo que el Mundial 78 aún no haya propiciado una obra de más largo aliento. La excepción es, sin dudas, la tesis de Sobocinski Marczal (2016), que se embarca en la reconstrucción de los discursos hegemónicos y contrahegemónicosde la prensa.

En líneas generales, tanto en la literatura que aborda la historia del fútbol como la dedicada a la última dictadura, el Mundial 78 aparece como un escenario secundario, un hecho de segundo orden. Quizá esto obedezca a que el mundial constituye una pieza de abordaje incómodo, en tanto propone un enlace complejo 
entre política, autoritarismo, nacionalismo, deporte y cultura popular. Se trata de un acontecimiento extraordinario tanto en la historia represiva de la dictadura como en el devenir de la espectacularización del fútbol. Tal vez, esa peculiaridad y ese estado de excepción que circundan al Mundial 78 puedan contribuir a su (re)problematización.

En esta comunicación presento tres focos que hacen a la gubernamentalidad del evento: primero, la generación de sus condiciones de posibilidad: la construcción de infraestructuras urbanas y comunicacionales; segundo, los núcleos de convergencia desplegados entre las tecnologías del gobierno militar sobre el ámbito socioeconómico y del gobierno futbolístico sobre el equipo, y tercero, el desarrollo paradójico de movimientos y corporalidades contenidas y reguladas en la ceremonia inaugural y unos cuerpos-movimientos apenas encausados en los festejos callejeros luego de la final.

\section{HACER AMBIENTE: INFRAESTRUCTURAS Y COMUNICACIONES}

...aquella época de vergüenza y demagogia desenfrenada [se refiereal tercer peronismo] con un afán desmedido de levantar monumentos que sólo respondían a fantasías carentes de racionalidad.

Osvaldo Cacciatore

La preparación del evento tuvo algunas palabras clave: modernización, infraestructura y comunicaciones. La acción gubernamental de la dictadura buscó emparentarse con el desarrollismo, pero añadió a sus recetas clásicas una mayor despolitización y austeridad. Como continuadora de ese modelo económico, la dictadura impulsó una modernización tecnocrática y un desarrollo administrativo y autoritario. Durante los aprestos del campeonato, la participación popular se mantuvo anulada. Las masas ocuparon coliseos ya terminados, listos para albergarlas. Sin embargo, su aparición final fue muy relevante, dado que reconfiguró en parte el tablero de juego. La emergencia de las multitudes en los festejos callejeros replanteó, momentáneamente, lo que podía hacerse y decirse en dictadura.

En el ambiente de la modernización despuntaron los expertos contratados, las asesorías empresariales, la terciarización y la patria contratista. La tecnología de gobierno para enlazar ese evento deportivo al proyecto de la dictadura fue el Ente Autárquico Mundial 78 (EAM 78). Ese dispositivo institucional mostraba la nueva silueta empresarial de un Estado que iniciaba su derrotero en la apropiación y redistribución discrecional de los recursos públicos. Así, se desplegó un volumen importante de obras. En tres subsedes del interior (Córdoba, Mar del Plata y Mendoza) se construyeron estadios nuevos. Arquitectos e ingenieros debieron lidiar con problemas puntuales. En el caso de Mar del Plata, la situación generada por los fuertes vientos determinó el reforzamiento de las estructuras de soporte. En Mendoza se practicó un socavado del terreno para colocar el estadio bajo nivel y no afectar el paisaje precordillerano.Mientras que en Rosario y Buenos Aires se acondicionaron los estadios de River Plate, Vélez Sarsfield y Rosario Central. Tres criterios orientaron las localizaciones: el arraigo del fútbol, la preexistencia de funciones urbanas densas y los atractivos turísticos. Esta tríada estableció por defecto las subsedes de Mendoza, Mar del Plata y, en menor medida, Córdoba, solo por completo acuerdo con los dos últimos criterios. La ausencia del primer elemento determinó un futuro de subutilización para los estadios. También se montaron los centros de prensa. En este sentido, la obra más espectacular fue el edificio de la planta transmisora de Televisión Argentina Mundial 78. El edificio de lo que luego sería ATC (Argentina Televisor a Color) intentaba borrar una de las obras inconclusas del peronismo: el Altar de la Patria. Ingenieros militares dinamitaron los cimientos de un monumento, cuya figura central hubiera sido el descamisado. La infraestructura para las nuevas transmisiones televisivas a color se opuso a otra menos neutra, más politizada, con mayor carga simbólica-ritual y menor capacidad tecnológica-funcional (Santangelo, 2014). Las huellas que el peronismo había impreso en el tejido urbano de Buenos Aires debían ser tachadas. Así, se inició una campaña feroz en pos de la erradicación de las villas miserias (Blaunstein, 2006). La ciudad necesitaba exhibir su parte más favorecida al mundo. La zona norte de Buenos Aires fue la más intervenida y el sur quedó relegado. Poco importó a los organizadores la 
proximidad ( 800 metros) entre el Estadio Monumentalde RiverPlate (corazón del torneo) y la Escuela de Mecánica de la Armada (núcleo del aparato represivo).

En las subsedes se mejoró la conectividad caminera, se remodelaron y acondicionaron las terminales de transporte aéreo y terrestre, se construyeron centros de prensa,comunicación y hoteles. Las inversiones plantearon un desbalance presupuestario que contrastaba con el ascetismo de la gestión económica. El debate en torno al gasto del evento suscitado entre Lacoste (vicepresidente del EAM78) y Alemann (secretario de Hacienda) mostró algunas de las fracturas intestinas del gobierno dictatorial.

En el plano de modernización de infraestructuras, la dictadura se presentó como un desarrollismo renovado. Las licitaciones fueron orquestadas para favorecer a contratistas y la toma de decisiones fue restringida a los expertos. La imagen modernizadora aspiraba a la homogeneidad y a la ausencia de debates. A pesar de las controversias alrededor del gasto y el orden, el modernismo autoritario producía disciplina productiva,despolitización, contratos interesados y obras públicas monumentales y funcionales. Esa disciplina administrativa y la materialidad de las infraestructuras configuraban el principal combustible del "modernismo autoritario". La dictadura exhibía sus obras, sus logros en materia de logística, y organización como el fruto de un conjunto de decisiones técnicas y administrativas neutrales.

\section{TECNOLOGÍAS DE GOBIERNO: SOCIEDAD Y FÚTBOL}

...respeten sus convicciones. Nuestra obligación es hacer lo imposible por darle a la gente, a nuestra gente un espectáculo inolvidable [...] Jueguen siempre. La lucha es un ingrediente más del fútbol. El que da batalla no debe olvidarse de jugar nunca. Cesar Luis Menotti

La gubernamentalidad socioeconómica de la dictadura se fundaba en una mezcla enmarañada e inestable de modernización y neoliberalismo. Por su parte, la gubernamentalidad futbolística estimulaba una modernización disciplinaria y colectivista de un juego antes concentrado en la habilidad y el talento individuales. Ambos modos de producción -el de una nueva economía política en las relaciones Estadomercado-empresas, y el de una nueva subjetividad entre los trabajadores-profesionales-futbolistas- se relacionaban con la modernización, la importación de modelos extranjeros y la conservación de valores esenciales, y eran denominados“proceso”. Tenían el objetivo común de hacer competitivas a la economía, la sociedad, las instituciones y el estilo futbolístico argentinos. Una misma racionalidad mercantil, empresarial, competitiva y despolitizadora orientaba su lógica.

El proyecto socioeconómico de la dictadura principiaba con una fuerte ofensiva contra las formas de politización que problematizabanal capitalismo hegemónico. La dictadura diseñó un plan sistemático de secuestro, reclusión, tortura y exterminio de seres humanos cuyas prácticas políticas estuvieran familiarizadas con cuatro movimientos: el peronismo de montoneros, el marxismo trotskista, el sindicalismo de base y la teología de la liberación. La dictadura desarticuló las organizaciones políticas en el espacio público, las obreras en las fábricas y las territoriales en los barrios. El blanco principal fueron los militantes de izquierdas, los delegados del sindicalismo clasista y las organizaciones de base. El exterminio de las expresiones políticas disidentes fue la condición de posibilidad de la modernización de la infraestructura y de la campaña de publicidad lanzada alrededor de ella. La disolución de una parte significativa de la industria nacional, la degradación de las condiciones de trabajo, la apertura de la economía a las importaciones y el reforzamiento de la nueva razón de Estado fomentaban la difusión de los mecanismos de mercado y la consolidación de las instituciones empresarias.

En el plano futbolístico, el técnico del seleccionado también tomó decisiones para desmarcarse de sus predecesores. Su figura quedó atravesada por componentes paradójicos y ambiguos: desde su vinculación al Partido Comunista hasta su blindaje mediático -favorecido por la dictadura-, pasando por su magnetismo personal, su retórica modernista y esencializadora, y su trabajo corporal y psicológico sobre los jugadores que combinaba el entrenamiento físico con la arenga motivacional. 
Comandado por Menotti, el "proceso" del Seleccionado Nacional no se desplegaba en el tiempo corto. Los jugadores contaban con una infraestructura y una planificación sistemática y de largo plazo. El "proceso" tampoco se recostaba sobre individualidades. Los nombres no destacaban por encima del conjunto. El técnico sostuvo que en la selección argentina no existía un jugador imprescindible. Para alcanzar un nivel internacional, el equipo debía entregarse a una movilidad permanente, capaz de erradicar la lentitud del fútbol argentino tradicional. Había una voluntad de introducir nuevos atributos en el juego: movilidad funcional, defensa coherente, zonal y sistemática, achique hacia adelante, un mediocampo con toque corto, buen control y escaso traslado lateral. Estos elementos implicaban la movilización de los cuerpos de los jugadores, una rigurosa preparación física y una mayor sincronización colectiva. El correcto estado físico, la coordinación de los movimientos, la concentración desarrollada con muchos meses de anticipación y las arengas en pro de cultivar unas convicciones y un temperamento firmes resultaron elementos clave del "proceso" futbolístico.

\section{Regular la PASión}

...los argentinos pueden ser ordenados y disciplinados, cuando reciben y acatan órdenes. He aquí una muestra incontrovertible: la ceremonia inaugural del mundial 78.

Diario Los Andes, Mendoza, 2/05/1978

La ceremonia inaugural constituyó una representación atravesada por el deseo de obtener reconocimiento y estuvo dirigida tanto a nacionales como a extranjeros. Esos minutos mostraron movimientos gimnásticos individuales y coreografías colectivas. Jóvenes de las escuelas medias integraron un conjunto de cuerpos asexuados y encapsulados en trajes blancos. El movimiento exhibía la coordinación de un organicismo orquestado al son de los silbatos. El ensamble transmitía jerarquía, orden, disciplina, higiene, organicismo, asexualidad, neutralidad, equilibrio, coordinación, acople y disolución del individuo en el conjunto.

A pesar del paso de las delegaciones extranjeras y de las banderas, las señas de multiplicidad y diferencia fueron casi suprimidas; la homogeneidad era transmitida por la corporalidad dócil y las figuras despolitizadas. La prensa reforzó el alcance y la brillantez de la performance. Todavía hoy, los espectadores recuerdan esa puesta como un momento importante del torneo.

Estas imágenes contrastaban con los festejos, menos atentos a los silbatos y a los ritmos de la orquesta militar que a la estridencia de las bocinas, los cánticos y los bombos. Las celebraciones canalizaron el crescendo de un entusiasmo que apareció con claridad después del partido ante Polonia. La tensa calma que dominaba las calles de Rosario antes y durante el encuentro fue desarticulada con la finalización del cotejo. Entonces, una marea humana copó la ciudad. Sin orden, disciplina ni regularidad esa multitud se movilizó. Automóviles, peatones, hombres, mujeres, niños llevaron banderas, cornetas, bombos; se vistieron con los colores de la selección y produjeron alboroto. En esas movilizaciones espontáneas pudo escucharse una euforia masiva que contrastaba con los movimientos planificados y mecánicos de la inauguración. Un abismo se extendía entre el ensamble coordinado del comienzo, la vigilancia cotidiana de las calles y las multitudes desenfrenadas de la gran final. En esa brecha prosperaban las fuerzas y las potencias de la multitud: espontaneidad, libertad y autoorganización. El repertorio de las movilizaciones finales estaba fijado por un código futbolístico y no por los deseos y las fantasías castrenses inaugurales.

Esos festejos populares se desplegaron sobre los centros urbanos de la Argentina.La calle emergió como un espacio tomado por unas multitudes espontaneas y apasionadas. Como muy pocas veces durante la dictadura, la ciudad fue un punto de fuga en un orden rígido, autoritario y excluyente. Pero ese espacio de encuentro debía mantenerse como una "excepción regulada". La calle fue separada de sus potencias para articular fórmulas de resistencia e insumisión. Los medios de comunicación hegemónicos intentaron fijar un sentido homogéneo para esa performance. Buscaron emparentar esas celebraciones carnavalescas con las exhibiciones gimnásticas de la inauguración. Sin embargo, al yuxtaponer las imágenes y los discursos sobre 
ambos momentos, aparece un excedente, una incongruencia narrativa. La multiplicidad no pudo ser por completo confinada en el nosotros autoritario y en el todos excluyente de un discurso prefabricado.

\section{Conclusiones}

En la construcción de infraestructura la dictadura ensayó mostrarse como la continuación autoritaria y, por lo tanto, más eficaz del desarrollismo. La producción de la red de comunicaciones se consagró a irradiar una imagen de la Argentina como país moderno. El gobierno dictatorial fantaseaba con que ese desarrollo promovería el disciplinamiento social y político. En ese imaginario, la tecnificación operaba como una suerte delenitivo sobre las utopías políticas del período previo.

Las macropolíticas económicas y sociales hallaron un correlato micropolítico en el gobierno de la selección a lo largo del llamado "proceso". La esencia nacional del fútbol argentino debía superar una prueba de hibridación con el orden y el sistema moderno europeos. Esta nueva "filosofía futbolística", al igual que el desarrollismo, requería disciplina, preparación física, coordinación sistemática, sacrificio y acoplamiento al juego colectivo.

Aunque la performance del equipo no fuera demasiado virtuosa, los simpatizantes comenzaron a entusiasmarse con algunas victorias decisivas. Los hinchas en las calles festejaron a la selección. Gran parte de los medios de comunicación registraron esas manifestaciones como un apoyo civil al gobierno. Esas multitudes llenaron con su alegría el hueco dejado por el juego gris del seleccionado. Compusieron estrategias apasionadas para apropiarse de los espacios vigilados por la gubernamentalidad militar. Las potencias que las multitudes desplegaron sobre las calles céntricas de las mayores ciudades argentinas, los intersticios que esa diferencia abrió en el orden autoritario,y la ausencia de cualquier tipo de organización y disciplina debieron ser cancelados por la dictadura. Las estrategias simbólicas del gobierno ensayaron borrar el potencial de una de las primeras manifestaciones masivas desde el golpe de 1976. La apuesta estuvo consagrada a encapsular los excedentes no futbolísticos de sentido que transportaban los festejos. Las potencias populares fueron domesticadas y despojadas de atributos revulsivos a través de la retórica de la unanimidad nacional, el énfasis en el triunfo de la organización, y la planificación sistemática y eficaz desplegada tanto por el gobierno como por el seleccionado y su director técnico.

\section{BibLIOGRAFÍA}

Alabarces, P. (2002). Fútbol y patria: el fútbol y las narrativas de la nación en la Argentina. Buenos Aires: Prometeo. Alabarces, P. (2014). Héroes, Machos y patriotas. El fútbol entre la violencia y los medios. Buenos Aires: Aguilar.

Archetti, E. (2004) El mundial de fútbol de 1978 en Argentina: victoria deportiva y derrota moral. Memoria y civilización 7(7) 174-194.

Blaunstein, E. (2006). Una historia de los planes de erradicación de villas de la última dictadura. Buenos Aires: Cuadernos de Causa Popular.

DalMasetto, A. (1998). Hay unos tipos abajo. Buenos Aires: Sudamericana.

Ferrero, L. y Sazbón, D. (2007) “Argentina '78: La nación en juego”, Caravelle, 89(89) 139-155.

Gilbert, A. y Vitagliano, M. (1998). El Terror y la Gloria. La vida, el fútbol y la política en la Argentina del Mundial '78. Buenos Aires: Norma.

Kohan, M. (2002). Dos Veces Junio. Buenos Aires: Sudamericana.

Llonto, P. (2005). La Vergüenza de Todos. El dedo en la llaga del Mundial '78. Buenos Aires: Ediciones Madres de Plaza de Mayo.

Santángelo, M. (2014). “Un mundial a colores: arqueología de un predio”, en Registros 10(10-11) 134-149. 
Sobocinski Marczal, E.(2016). ¿Qué otra cosa se puede festejar? Paixao e política nas narrativas sobre a copa do mundo de futebol na Argentina (1975-1978), (Tesis doctoral). Universidade Federal do Paraná. Curitiba. Recuperada de https://acervodigital.ufpr.br/bitstream/handle/1884/44987/R-T-ERNESTOSOBOCINSKIMARCZAL. pdf? sequence $=1 \&$ isAllowed $=y$ 